\title{
Stress-resilient maize for climate-vulnerable ecologies in the Asian tropics
}

P.H. Zaidi ${ }^{1,}{ }^{*}$, Thanh Nguyen ${ }^{2}$, Dang N. Ha ${ }^{2}$, Suriphat Thaitad ${ }^{3}$, Salahuddin Ahmed ${ }^{4}$, Muhammad Arshad ${ }^{5}$, Keshav B. Koirala ${ }^{6}$, Tirtha R. Rijal $^{6}$, Prakash H. Kuchanur ${ }^{7}$, Ayyanagouda M. Patil ${ }^{7}$, Shyam S. Mandal ${ }^{8}$, Ramesh Kumar ${ }^{9}$, S.B. Singh ${ }^{9}$, Bhupender Kumar ${ }^{9}$, J.P. Shahi $^{10}$, M.B. Patel ${ }^{11}$, Murali K. Gumma ${ }^{12}$, Kamal Pandey ${ }^{13}$, Ramesh Chaurasia ${ }^{14}$, Azizul Haque ${ }^{15}$, K. Seetharam ${ }^{1}$, Reshmi R. Das ${ }^{1}$, M.T. Vinayan $^{1}$, Zerka Rashid ${ }^{1}$, S.K. Nair ${ }^{1}$ and B.S.Vivek ${ }^{1}$

${ }^{1}$ CIMMYT Asia Maize Program, ICRISAT campus, Patancheru-502324, Hyderabad, India

${ }^{2}$ National Maize Research Institute, Ha Noi, Vietnam

${ }^{3}$ Nakhan Suwan Field Crop Research Center, Tak Fa, Nakhan Sawan, Thailand

${ }^{4}$ Bangladesh Agricultural Research Institute, Gazipur, Bangladesh

${ }^{5}$ Maize \& Millet Research Institute, Sahiwal, Pakistan

${ }^{6}$ National Maize Research Program, Rampur, Chitwan, Nepal

${ }^{7}$ University of Agricultural Sciences, Raichur, Karnataka, India

${ }^{8}$ Bihar Agriculture University, Sabor, India

${ }^{9}$ Indian Institute of Maize Research, Ludhiana, Punjab, India

${ }^{10}$ Institute of Agricultural Sciences, BHU, Varanasi, U.P., India

${ }^{11}$ Main Maize Research Station, Gujarat Agriculture University, Godhara, Gujarat, India

${ }^{12}$ International Crops Research Institute for Semi-arid Tropics, Hyderabad, India

${ }^{13}$ Corteva AgriSciences, Hyderabad, India

${ }^{14}$ Kaveri Seeds Pvt. Ltd., Hyderabad, India

${ }^{15}$ BRAC, Dhaka, Bangladesh

*Corresponding author: phzaidi@cgiar.org

Abstract

Most parts of the Asian tropics are hotspots of climate change effects and associated weather variabilities. One of the major challenges with climate change is the uncertainty and inter-annual variability in weather conditions as crops are frequently exposed to different weather extremes within the same season. Therefore, agricultural research must strive to develop new crop varieties with inbuilt resilience towards variable weather conditions rather than merely tolerance to individual stresses in a specific situation and/or at a specific crop stage. $\mathrm{C}_{4}$ crops are known for their wider adaptation to range of climatic conditions. However, recent climatic trends and associated variabilities seem to be challenging the threshold limit of wider adaptability of even C4 crops like maize. In collaboration with national programs and private sector partners in the region, CIMMYT-Asia maize program initiated research for development (R4D) projects largely focusing on saving achievable yields across range of variable environments by incorporating reasonable levels of tolerance/resistance to major abiotic and biotic stresses without compromising on grain yields under optimal growing conditions. By integrating novel breeding tools like - genomics, double haploid (DH) technology, precision phenotyping and reducing genotype $\times$ environment interaction effects, a new generation of maize germplasm with multiple stress tolerance that can grow well across variable weather conditions were developed. The new maize germplasm were targeted for stress-prone environments where maize is invariability exposed to a range of sub-optimal growing conditions, such as drought, heat, waterlogging and various virulent diseases. The overarching goal of the stress-resilient maize program has been to achieve yield potential with a downside risk reduction.

Keywords: Climate change; Stress-resilience; Maize; Zea mays L.; Weather extremes.

\section{Introduction}

Maize emerged as the cereal with the largest global production, surpassing rice in 1996 and wheat in 1997, with production increasing twice the annual rate in rice and thrice in wheat (Fischer et al., 2014). Asia is the second largest producer of maize, with a $31 \%$ share from about $34 \%$ of the total area harvested. The impressive growth in maize production continued in current decade in the region- (Fig. 1), including Southeast Asia (10.8\%), South Asia (27.3\%), East Asia (30.6\%), which resulted in an overall $27.7 \%$ increase in Asia during 2010 and 2016 (FAOSTAT, 2018). On the other hand, the exponential increase in global maize demand has outstripped its global production. Maize has been identified as the cereal with the highest estimated global demand by 2020; a $45 \%$ increase in demand compared to $30 \%$ for wheat and $32 \%$ for rice. Asia's demand for maize is projected to rise 
sharply ( $87 \%$ rise by 2020) as compared to its demand in 1995 (IFPRI, 2003). Among Asian countries, the highest demand is projected in countries of East Asia, largely China that alone would require 252 million MT, followed by Southeast Asia requiring 39 million MT and South Asia 19 million MT (Fig. 2a). An array of factors are contributing to this sharp increase in demand, including growing per capita GDP (gross domestic product), changing diets and a significant rise in feed use driven largely by a rapidly growing poultry sector (Shiferaw et al., 2011). This has significant implication on maize production in the region. The exponential increase in demand in the region is largely driven by the feed sector and therefore, despite the impressive growth in production, Asia region remains largest importer of maize grain (Fig. 2b). By 2020, the global area growth for maize is expected to increase by only $12 \%$ compared to the maize area in 2000 . Thus, $88 \%$ of the required increase in production will have to be met from increased productivity per unit area of land (James, 2003); a daunting challenge for maize farmers in the developing world who grow the crop on about two-thirds of the global maize area.

Most of the maize in the Asian tropics is grown in lowland tropics (<1000 masl), including both dry and wet-lowlands, followed by sub-tropical/mid-altitude and tropical highlands (Zaidi et al., 2014). Maize is largely ( 80\%) grown as a rainfed crop, prone to the vagaries of monsoon rains, associated with an array of abiotic and biotic constraints. This is reflected in maize productivity under rainfed conditions, which is usually less than half compared to irrigated conditions. In general, there is considerable pressure on irrigation water, resulting in increased irrigation intervals that subject the crop to stress and a consequent reduction in grain yields. Moisture availability is seldom adequate in rainfed conditions. Erratic/un-even distribution pattern of monsoon rains often cause intermittent drought or excessive moisture/waterlogging at different crop growth stage(s) within the same season (Zaidi et al., 2016a), a major factors responsible for relatively low productivity of rainfed maize. Uncertainty of assured returns often discourage maize farmers to investing on recommended cropping management practices, which result in low soil fertility and eventually add in poor yields. In recent years the Asian tropics have experienced frequent and widespread severe drought years. A few examples are the seven drought in South Asia since 2000, coupled with increased day/night temperatures during the main maize growing season (monsoon season), apart from scattered drought/heat almost every year in one country/subregion or the other.

Maize is highly vulnerable to reproductive stage drought and/or high temperature stress. Spring maize in the Asian tropics grown during the hot summer (Feb-May) is invariably exposed to high temperature regimes during most of the critical crop growth period, starting from late vegetative stage until early grain filling stage. Also, in drought years in the summer-rainy season (the main crop season for maize in Asia) temperature (both $\mathrm{T}_{\max }$ and $\mathrm{T}_{\min }$ ) rises close to or beyond threshold limits, which might result in severe stress conditions due to the combination of drought and heat stresses (Fig. 3). An assessment of the impact of current and future heat stress on maize in South Asia has clearly shown that areas affected by heat stress will significantly increase in the future, particularly in the pre-monsoon (spring) and monsoon (rainy) seasons (Tesfaye et al., 2017). The study also highlighted the potential yield advantage of heat tolerant maize varieties in both spring and rainy seasons, relative to current heat-vulnerable maize varieties that are extensively grown in the region.

The lowland tropics, especially wet lowland, are most conducive for an array of diseases of economic importance (Rashid et al., 2013). Turcicum leaf blight (Exserohilum turcicum), Maydis leaf blight Helminthosporium maydis, rust (Puccinia polysora) and downy mildew (Pernosclerospora spp.) are the most common diseases in Asian maize. Though Asian maize germplasm contain reasonable sources of resistance to these diseases new diseases or the evolution of more virulent strains pose a major challenge to the available host-plant resistance, causing an outbreak within short period. Rashid et al. (2013) showed that out of 19 downy mildew resistant maize lines released as trait donors only 5 could maintain their resistance levels (Fig. 4). Therefore, host-plant resistance breeding programs require close monitoring of changes in the virulence of pathogens and the identification of new resistance sources. Banded leaf and sheath blight (BLSB) have emerged as a major threat in many parts of the Asian tropics, especially where rice-maize rotation is followed, with no good sources of resistance against the disease. Maize in the region is also prone to several stalk rot diseases caused by a range of causal organism (Rashid et al., 2018b). While Diplodia ear rots are most common, Fusarium, Macrophomina spp. causing stem rots are prevalent after a dry spell. Under humid conditions at harvesting, Aspergillus ear rots are prevalent in hybrids with poor husk cover; so is insect damage that often leads to dangerous levels of mycotoxin in maize grains.

\section{Climate change effects in the Asian tropics: Dealing with uncertainties}

Rainfed systems represent a major part of the maize megaenvironments in the Asian tropics. They are largely dependent on prevailing weather conditions and therefore extremely vulnerable to climate change effects. Studies suggested that Asia will experience increasing frequency of extreme weather conditions with high variability beyond current capacity to adapt (ADB, 2009; Cairns et al., 2012). Climate modelling studies suggested a sharper increase in both day and night temperatures in the near future that could adversely impact maize production in the tropical regions (Cairns et al., 2012; Lobell et al., 2011). Such impacts are evident in form of shifting seasons and significant inter-annual variation in rainfall (Fig. 5), with increased frequency of extreme weather causing severe drought and/or water-logging. One of the major effects of climate change has been the reduction in the number of rainy days in the Asian tropics in both South Asia (Kashyapi et al., 2012) and Southeast Asia (Manton et al., 2001;although there has been no significant change in total rainfall. The erratic distribution of monsoon rains results in extremes of water availability within the same cropping season, causing contingent/intermittent waterlogging at one crop stage and extended dry periods at another. Therefore, during the most critical crop growth period, the rainfed crop may be exposed to variable moisture regimes in the same area in different years. 
With increasing climate variability, agricultural research should focus on developing of crop varieties that are resilient to variable weather conditions within seasons, rather than only to tolerance to individual stresses at a specific crop growth stage. Plant breeders need to identify and deploy in the breeding pipeline new genes with physiological mechanisms that contribute to enhanced climate resilience. Recent advances in molecular breeding and biotechnology are contributing to engineering plants with tolerance to abiotic stresses. However, future efforts must focus on integrating multiple adaptation traits in new cultivars to provide resilience to a set of adverse conditions. Drought and heat stresses often occur at the same time due to their integrated nature in drought-prone environments. In general, breeding for heat-stress tolerance in crop plants has lagged behind compared to that for other abiotic stresses. An extensive screening of maize lines developed for drought-prone environments in the tropics has revealed that only a very few of them combine heat and drought tolerance traits. Heat and drought stress tolerance were poorly correlated suggesting that they are controlled by different genetic mechanisms (Cairns and Prasanna, 2018).

\section{Stress-resilient maize: option for current and future climate}

Challenged by growing food insecurity and climate change, Asian agriculture must become more productive, more resilient and more climate friendly. Crop varieties with increased resilience to abiotic and biotic stresses will play an important role in autonomous adaptation to climate change (Fedoroff et al., 2010). Millions of small holders in Asia grow maize under rainfed conditions for their subsistence. The future of maize production, and consequently, livelihoods of several million smallholder depends upon access to highyielding, stress-resilient rather than currently available highyielding but risky cultivars. Maize production can be sustained under adverse climatic conditions and may be further increased by using genetic diversity which harbours favourable alleles for high yield, biotic and abiotic stress tolerance (Prasanna et al., 2012). Targeted crop improvement, aided by precision phenotyping, molecular markers-assisted selection and breeding, and doubled haploid (DH) technology offer a powerful strategy to develop climate-resilient germplasm. The time lag between the development of improved germplasm and its adoption by farmers underscores the urgency of adopting such a strategy in tropical Asian countries most likely to be affected by climate change effects (Cairns et al., 2012; Prasanna, 2018). Using a crop growth simulation model for maize (CERES-Maize) Tesfaye et al., (2018) quantified the impact of climate change on maize and the potential benefits of incorporating drought and heat tolerance into commonly grown (benchmark) maize varieties at six sites in Eastern and Southern Africa and one site in South Asia. Simulation results indicated that climate change will have a negative impact on maize yields at all the sites studied, but the degree of impact varied with region, level of warming and rainfall changes. Combining hotter and drier climate change scenarios (involving increases in warming with a reduction in rainfall) resulted in greater simulated average maize yield reduction than only in the hotter climate change scenario. Incorporating combined drought and heat tolerance into benchmark varieties increased simulated maize yield under both baseline and future climate senerios. While further evidence is required to document the risk-reduction benefits of climate-resilient maize on the number of chronically poor farmers, an increasing body of evidence confirms the benefits in terms of increased yields, reduced yield variability and eventually increased food security (Cairns and Prasanna, 2018).

There is a myth that breeding for stress tolerance/resilience causes yield drag under optimal growing/high yield conditions. An extensive multilocation evaluation of stress-resilient hybrids along with popular commercial checks in sub-Saharan Africa (Banziger et al., 2006) and a recent study in Asia have demonstrated that a targeted breeding approach based on selection across stressed and optimal conditions can lead to the development of high-yielding, stress-resilient maize hybrids without yield penalties under optimal conditions (Fig. 6). In collaboration with national programs and private sector partners in the region, CIMMYT-Asia maize program has initiated several projects focusing on protecting achievable yields across environments by incorporating a reasonable level of tolerance/resistance into key stresses without compromising on yields under optimal conditions. Integrating genomics and field-based precision phenotyping and focusing on reducing genotype $\times$ environment interaction effects, a new generation of maize germplasm was developed with multiple stress tolerance that can grow well across varied weather conditions within or across seasons. These new generation maize cultivars are being targeted at climate-vulnerable, stress-prone environments where they are invariably exposed to a wide range challenges, such as drought, heat, waterlogging and biotic stresses. The aim has been to develop and deploy suitable maize germplasm for current climatic conditions and maintain a product pipeline to effectively feed the requirement of emerging challenges due to future climatic situations in the Asian tropics.

\section{Developing stress-resilient maize by integrating novel tools in mainstream breeding}

The overarching goal of developing the stress-resilient maize has been to improve yield potential along with downside risk reduction. In CIMMYT-Asia maize program we focused on enhancing resilience in maize germplasm for an array of climatic conditions. This is achieved by concentrating on the integration of the following key components:

- Base germplasm with key traits, i.e. constitution of the breeding population by intermating established trait donors for a set of traits for targeted environments along with elite high-yielding lines with proven commercial value;

- Integration of novel breeding tools, including genome-wide association studies (GWAS), genomic selection (GS) and double haploid $(\mathrm{DH})$ technology to fast-track the stress-resilience breeding pipeline;

- Field-based precision phenotyping for stress-adaptive traits along with grain yield at several representative sites under managed-stress screens and

- Research collaboration and partnerships to bring together committed partners, including both public sector $R$ \& $D$ programs and private sector seed companies in the region, for sustainable development, deployment and scaling out of climate-resilient cultivars in stress-prone agro-ecologies in the region. 
High yields under optimal conditions (yield potential) and reasonably good yields under sub-optimal conditions (stress tolerance) are not mutually exclusive. Therefore, achieving a balance between improved and stable yields across stressed and non-stressed environments (i.e. resilience across growing conditions) is possible by defining and selecting a strategy across a range of environments and selecting progenies with high stable performance across growing conditions. To increase the efficiency of stress-resilience breeding pipelines, CIMMYT-Asia maize program, together with NARS in the region have implemented an integrated approach that includes managed stress phenotyping, index selection for stressadaptive secondary traits along with grain yield under stress and non-stressed environments, and the use of novel breeding approaches such as GWAS, RC-GS and DH technology. The strategy has helped in developing new Asia-adapted maize germplasm pipelines with enhanced stress tolerance for individual stresses as well as products with resilience across stresses, without compromising on yield potential under optimal conditions, as described in the following sections.

\section{Constitution of base germplasm}

Base population is the foundation for the success of breeding program targeting stress-resilience for current as well as future climate. Constituting base population involving promising trait donors for relevant abiotic and biotic stresses along with germplasm with elite background (for yield potential) provide a solid based for selection of progenies with combination of traits along with high yields. In CIMMYT-Asia and Africa maize programs, association mapping panels were constituted involving 300-500 maize inbred lines representing genetic diversity of tropical maize. This includes, drought tolerant maize for Africa (DTMA) panel, CIMMYT Asia association mapping panel (CAAM) and heat tolerant association mapping (HTAM) panel. These panel were genotyped using various marker systems, including 1536 (Illumina-Golden Gate), 55K (Illumina-Infinium) and GBS (Genotyping by Sequencing around 900K SNPs). Across-site phenotyping data was generated under managed stress screens under key abiotic stress, including drought, heat, waterlogging and cold stress, and at hot-spot location with artificial inoculation for major diseases in lowland tropics. Genome-wide association studies was conducted separately for each trait and major genomic regions were identified that are associated with resistance to major diseases (Rashid et al., 2018a and b; Gowda et al., 2015; Gowda et al., 2018) and abiotic stresses, including heat or drought (Cerrudo et al., 2018; Yuan et al., 2019), waterlogging (Zaidi et al., 2015) and root traits (Zaidi et al., 2016d). These GWAS study resulted in following major outputs:

- Major genomic regions associated with drought, waterlogging or heat tolerance identified.

- Marker-assisted introgression of those regions in elite but susceptible Asia-adapted maize inbred lines with established commercial value.

- Promising trait donors with known genomic regions, for various abiotic and biotic stresses for use in breeding program for constituting new base populations for developing stressresilient maize germplasm for individual and/or combined stress tolerance through recurrent selection using RC-GS.

\section{Field-based precision phenotyping}

Irrespective of conventional or molecular breeding approach, high quality phenotyping is key to successful genetic improvement for targeted traits. To realize the success of a breeding program in terms of genetic gains, it is essential to appreciate the principles of phenotyping and their practical implementation in practice (Banziger et al., 2000; Zaidi et al., 2016b and 2016c; Zaman-Allah et al., 2016). Screening genotypes under natural/rainfed conditions with random stress may be highly chance-based, compromising on the efficiency and accuracy in identifying available genotypic variation and in the selection of superior genotypes with targeted traits. Managed stress phenotyping at a carefully selected location allows the application of a desired level of stress at a targeted crop stage with uniformity in terms of space, timing and duration (Zaidi, 2019). It helps in expressing genotypic variability available for the trait(s) and the selection of superior entries for use in breeding. Precision phenotyping involves a detailed characterization of the phenotype of test entries under well defined environment (i.e.- managed drought stress). This is critical for establishing genotypephenotype associations in marker-trait association and its use in marker-assisted selection/introgression of desired traits into elite genetic background. The quality of phenotypic data depends on the precision in the phenotyping environment. Understanding the target population of environment (TPE) and simulating similar but more precise and uniform conditions (managed stress) is a pre-requisite for generating quality phenotypic data (Zaidi et al., 2016b and 2016c; Zaman-Allah et al., 2016). Phenotyping sites need to be carefully chosen based on the following information:

- A minimum set of medium term (past 10 years) weather data (daily maximum and minimum temperatures, humidity and rainfall distribution);

- Soil characteristics - physical and chemical properties;

- Cropping history of the field;

- Field levelling, irrigation and drainage facility; and

- Common biotic stresses.

The overall purpose of a managed stress phenotyping is to simulate stress conditions, such as drought, with a desired level of intensity with uniformity across fields at a critical /targeted crop growth stage in a way that the available genotypic variability is clearly expressed and identified for selection and use in breeding (Zaidi, 2019).

\section{Trait-based selection along with yield under stress}

In general, the major trait of interest in most of the field crop, including maize, has always been grain yield. However, under abiotic stresses heritability of grain yield is usually low, while heritability of some secondary traits remains reasonably high, and the genetic correlation between those traits and grain yield increases (Edmeades et al., 1998). Also, selection based solely on grain yield under stress may sometime be misleading; for instance while selecting a high yielding test entry with prolonged anthesis-silking interval (ASI $>5.0$ days). Such hybrid can produce high yield in a field trial as it was fed by the synchronous availability of pollen from other test hybrids in the trial. However, such a hybrid may end up with very poor 


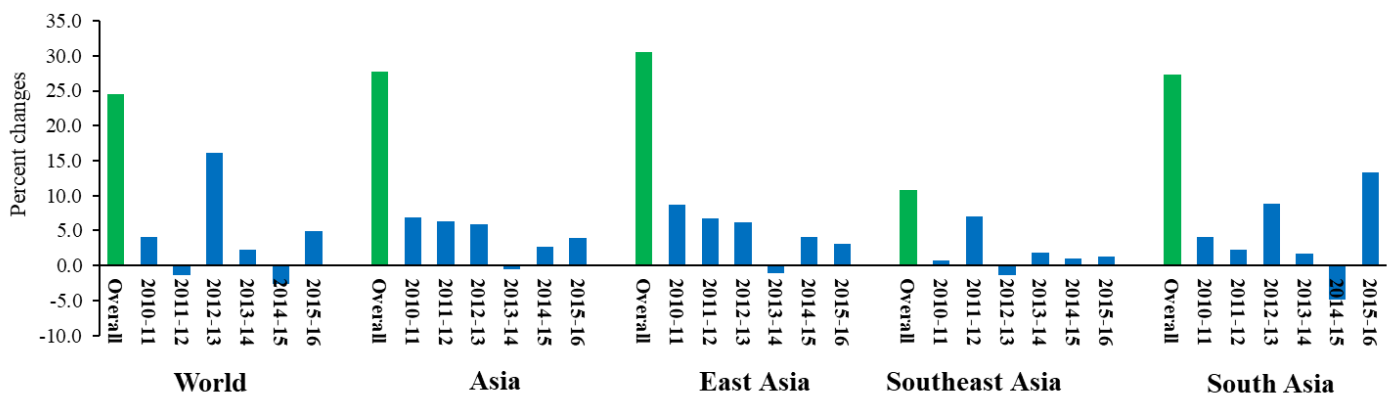

Fig 1. Growth in maize production during current decade (2010-2016) in various regions of Asia (Source: FAOSTAT, 2018).
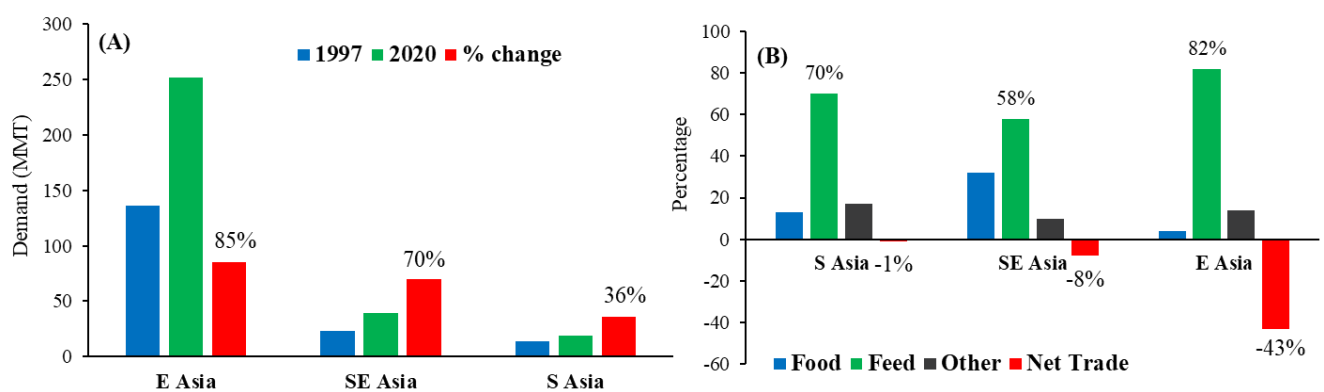

Fig 2. (A) Projection of maize demand and (B) consumption, and net trade [Source: FAOSTAT, 2018).

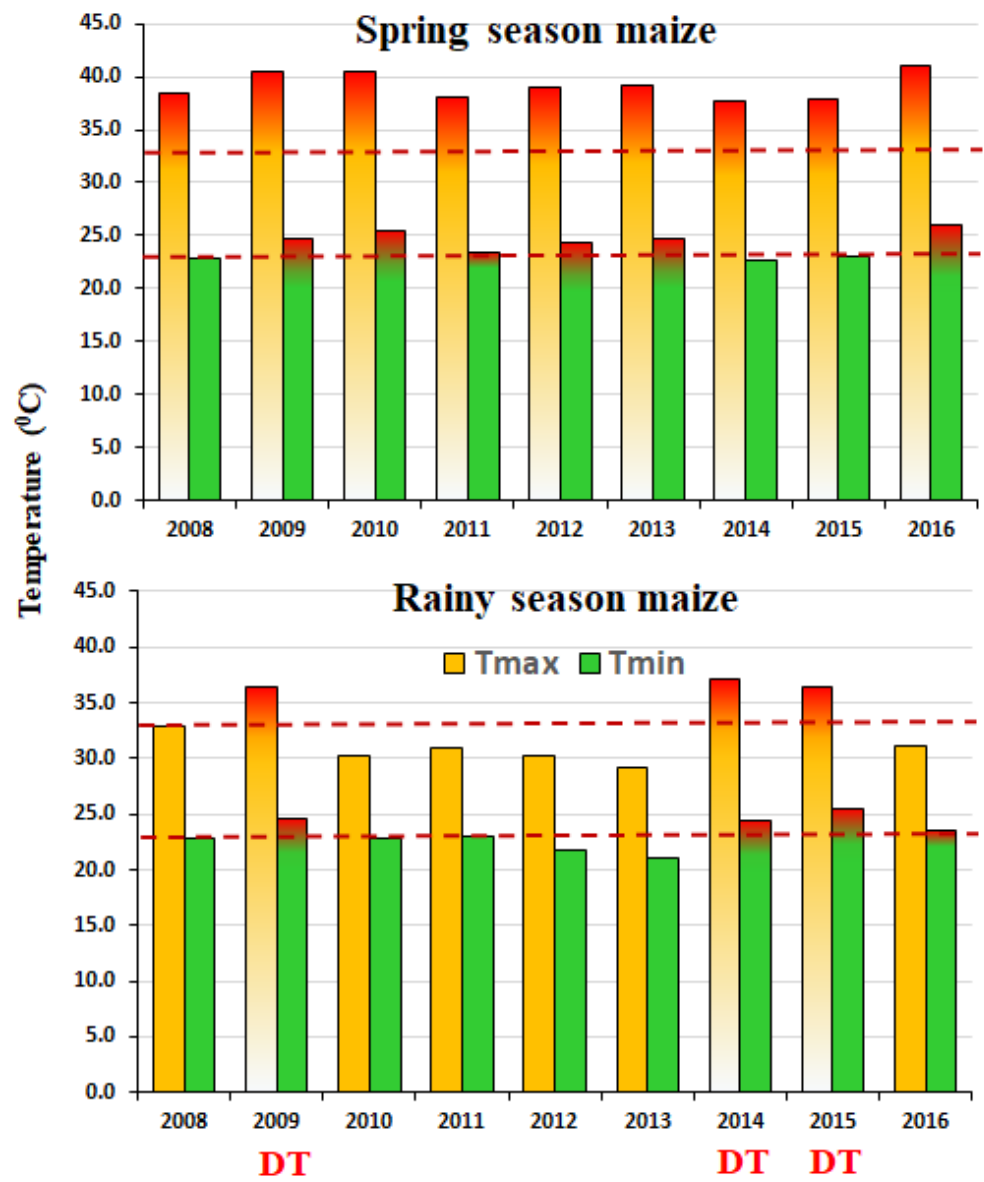

Fig 3. Temperature regime during flowering/grain-filling stage of maize in South Asia. 


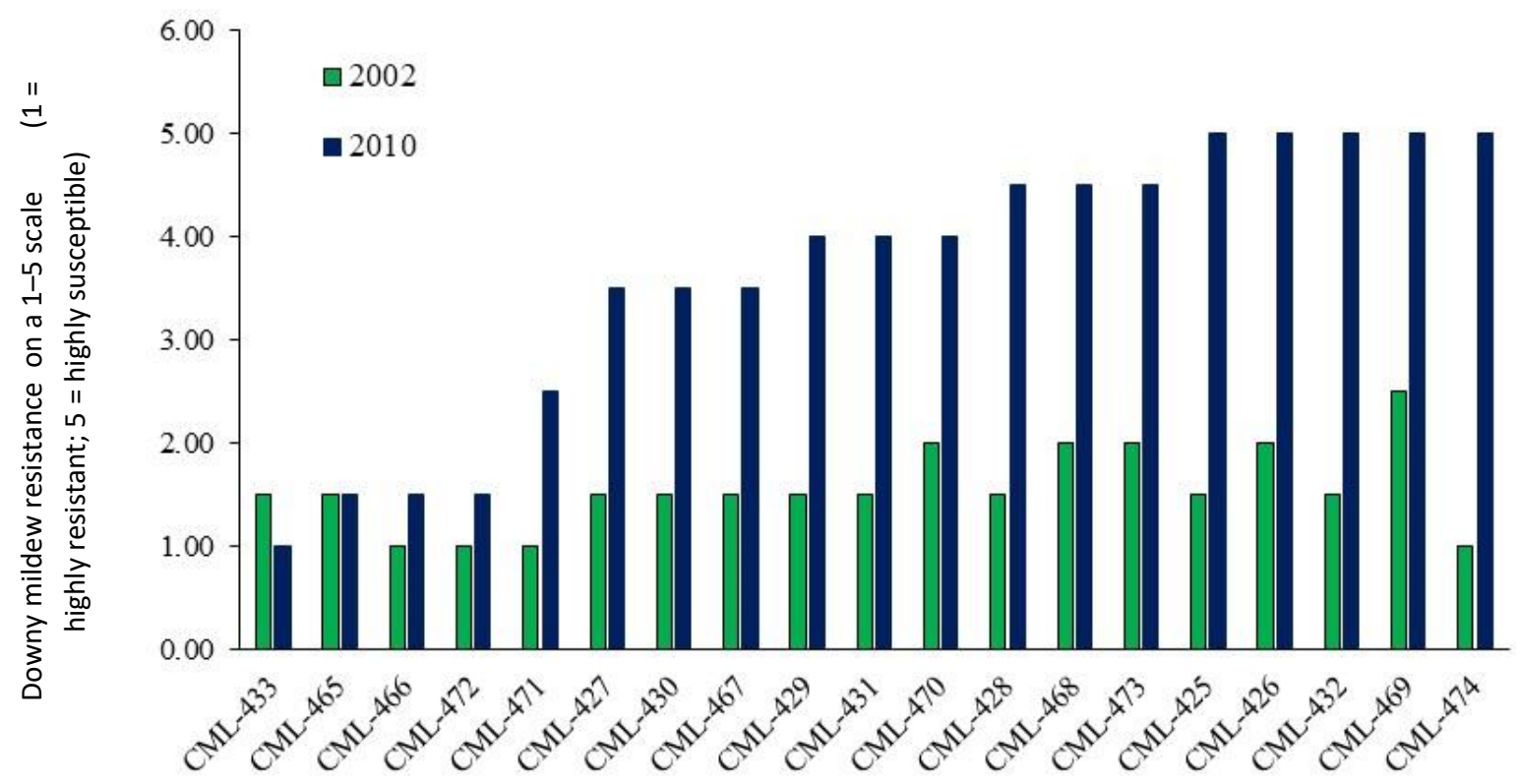

Fig 4. Change in downy-mildew resistance score of released CIMMYT maize lines (CMLs). $1=$ highly resistant; $5=$ high susceptible).

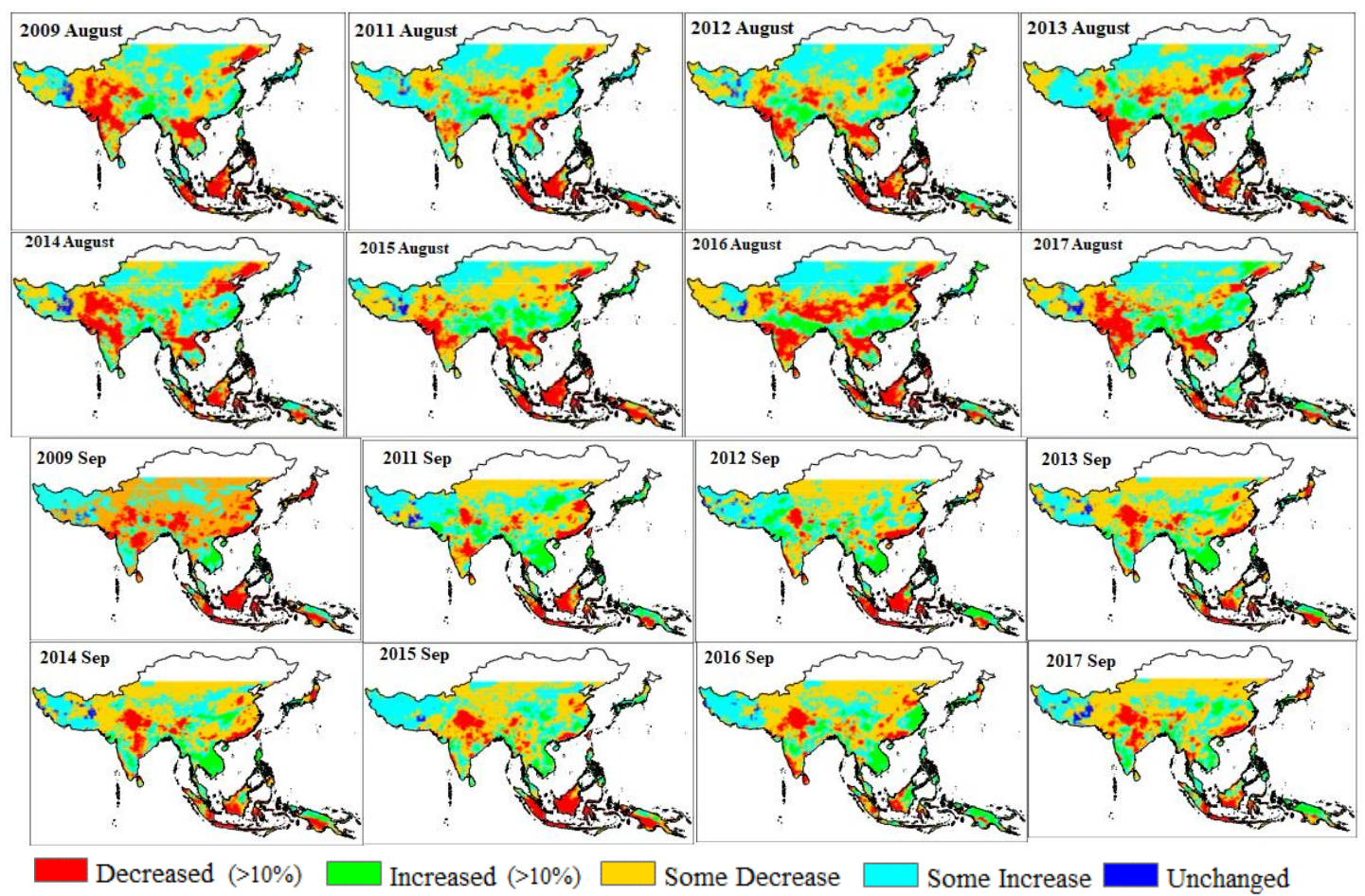

Fig 5. Variation in monsoon rains in the Asian tropics during 2009-2017 in relation to 2010 (reference year). 


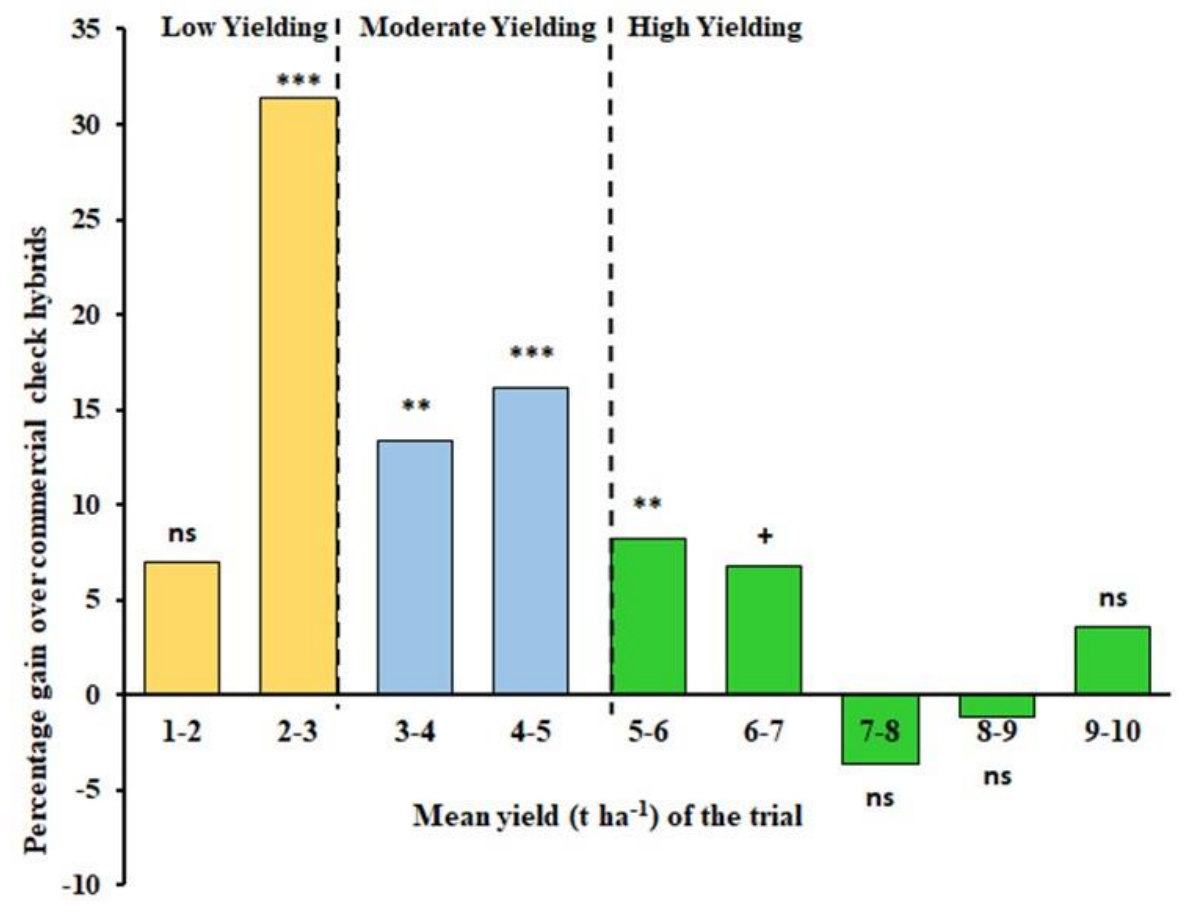

Fig 6. A comparision of yield gains between stress-resilient maize hybrids and high-yielding commecial checks evaluated across 52 locations in South and Southeast Asia.

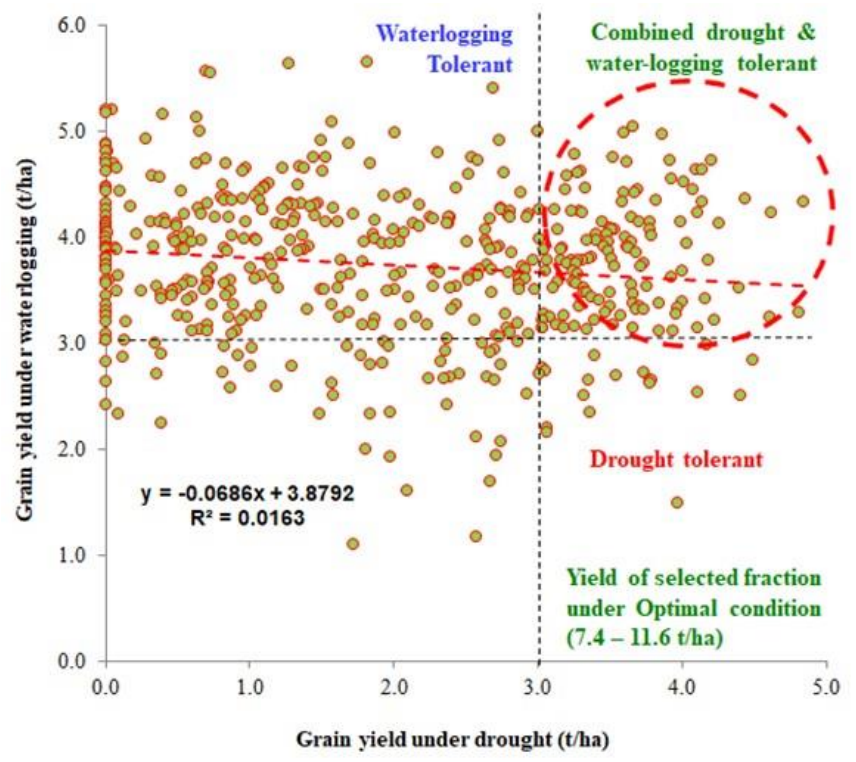

Fig 7. Selection of promising hybrid combinations across moisture regimes using managed stress screen, including drought, waterlogging and optimal moisture. 


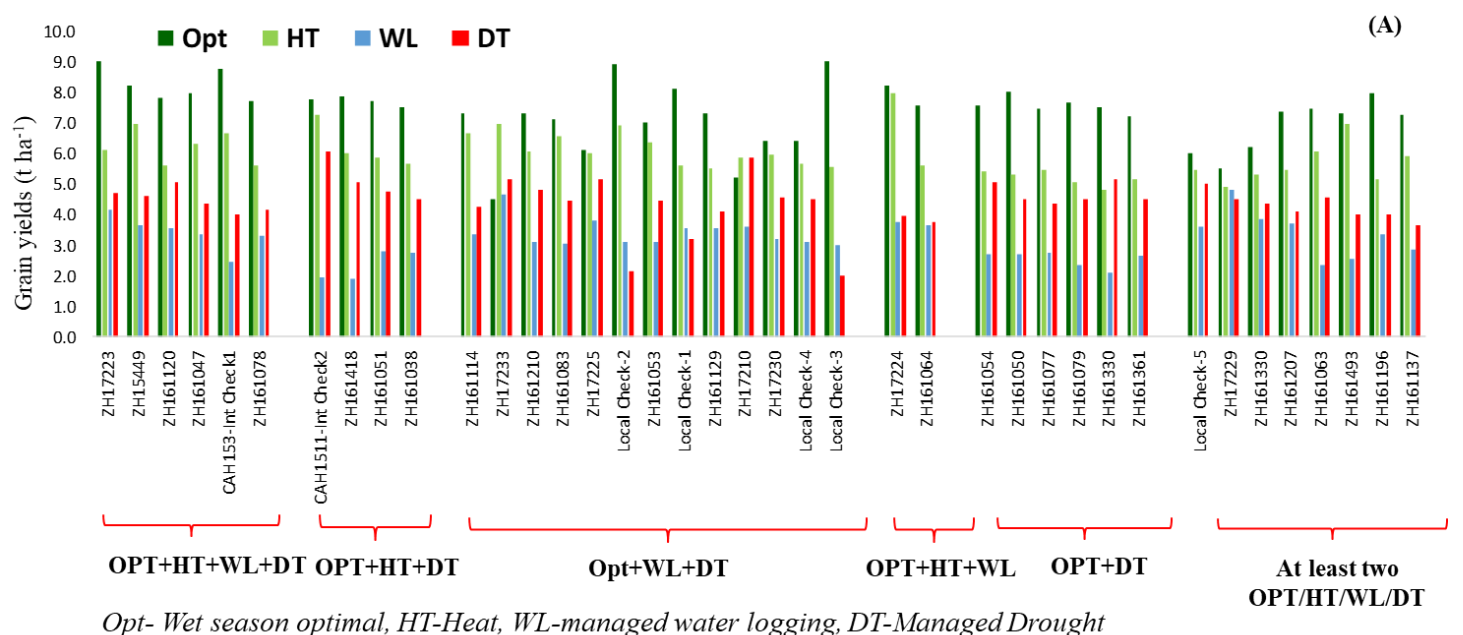

Opt- Wet season optimal, HT-Heat, WL-managed water logging, DT-Managed Drought

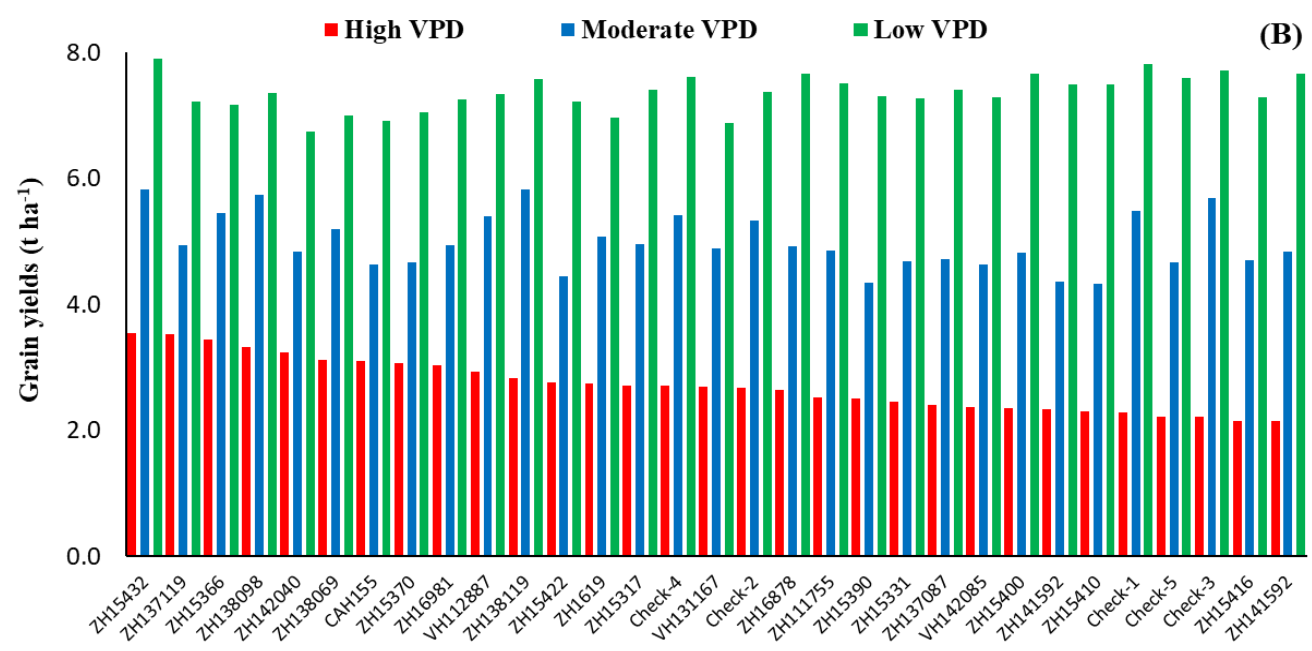

Low VPD sites = Tmax: $35-40^{\circ} \mathrm{C} ;$ VPD: $<3.0 \mathrm{kPa}$

Mod. VPD sites $=$ Tmax: $35->40^{\circ} \mathrm{C} ; \mathrm{VPD}: 3.0-5.0 \mathrm{kPa}$

High VPD sites $=$ Tmax: $35->40^{\circ} \mathrm{C} ;$ VPD: $>5.0 \mathrm{kPa}$

Fig 8. A choice of stress-resilient maize hybrids for various stress-prone ecologies: $(A)$ rainy season, prone to variable weather extremes and $(B)$ spring season prone to heat and vapor pressure deficit (physiological drought) stress.

(or even zero) yields in farmer fields where such a hybrid alone is planted in large area.

In molecular breeding, detailed phenotyping is required to support the huge volume of genotypic information generated and unearth valuable information. It is essential to dissect complex traits into components that can enhance an understanding of the cascade of event involved in conferring tolerance and add value to efforts in discoverying genomic region. However, for a secondary trait to be part of the phenotyping portfolio, the following basic requirements (Edmeades et al., 1998) are a must:

- Significant genetic variability exists for the trait and its breeding value must be established;

- The trait must have significant genetic correlation with grain yield under stress, i.e. - the relationship is causal, not casual;
- Broad-sense heritability for the trait is higher than grain yield itself, i.e.- it is less affected by genotype $x$ environment interaction;

- The trait should not be associated with poor yields under optimal conditions, i.e. - it must confer tolerance rather than avoidance and

- Rapid and reliable measurement and relatively less expensive than measuring yield itself.

High precision in managed stress trials in the field together with a system of applying the desired level of stress at a targeted crop stage is a must for generating high quality phenotyping data. Recent development in digital technologies is emerging as an option in enhancing efficiency and precision in data capture in field trials using high throughput precision phenotyping (HTPP) platform, including the use of a proximal or remote-sensing platform (Makanza et al., 2018). In order to understand and estimate genotype $\times$ environment interaction 
effects, multi-location phenotyping in at least 2-3 locations for each stress is a must. An affordable, low-cost and easy-tohandle field-based HTTP platform is therefore imperative and a key component in the breeding pipeline of stress-resilient maize breeding programs.

\section{New generation of stress-resilient maize hybrids First generation maize hybrids}

Large-scale robust phenotyping data on a GWAS panel has helped identify highly promising donor lines for various complex traits (abiotic and biotic stresses). These trait donor lines were used in various ways in breeding stress-resilient maize hybrids. First-generation maize hybrids were identified in two ways -

- Promising testcrosses from across site results of association mapping panel, as ready hybrid combination for individual stresses, and few hybrids, with stable performance across stresses and unstressed environments.

- Elite donor lines were identified after across site phenotyping of association mapping panel testcrosses with known heterotic pattern were crossed using north-Carolina design-II.

Hybrids from these two sources were evaluated across a range of both biotic and abiotic stresses and under optimal growing conditions. The best hybrids with a combination of traits (and respectable yields under optimal trial) were identified based on results from across location trials.

\section{Second generation maize hybrids}

Promising inbred lines in one or multiple stresses were used as trait donor in developing multi-parent synthetic populations (8-10 lines), which were used as a base population (Cycle-0 or $\mathrm{CO})$ in stress-resilience breeding program. These populations were advanced through RC-GS approach; C1 was constituted by inter-mating the top $5 \% \mathrm{~F}_{2: 3}$ progenies based on their testcross performance across several locations under stresses and non-stressed environments. Marker/haplotype/QTL effects were estimated by analysing genotype of $F_{2: 3}$ families and phenotype datasets from $F_{2: 3}$ test-crosses. Cycle 1 was improved through RC-GS to next two cycles (C2 and C3) using genomic estimated breeding values (GEBVs) for grain yield across stresses and non-stressed environments. The advanced cycles were subjected to $\mathrm{DH}$ induction. These $\mathrm{DH}$ lines were used in developing new hybrid combinations to identify a new generation of stress-resilient hybrids for South and Southeast Asia.

These hybrids have gone through stage-I testing across various stresses and optimal moisture conditions, along with promising $1^{\text {st }}$ generation hybrids and popular commercial hybrids as check entries in the trials. Selected hybrids across stresses and non-stressed environment (Fig. 7) were advanced to stage-II, and short-listed hybrids from stage-II were evaluated in at least two more stages, i.e. stage-III and MLT (multilocation testing in larger plots) in TPE, before finalizing best-bet hybrids for various types of stress-prone ecologies/market segments (Fig. 8) to be deployed and scaled out in collaboration with public sector institutions and seed company partners in the region.

\section{Partnership for efficient deployment and scaling-out}

A strong network of partnerships across locations spanning various agro-ecological conditions is crucial in stress-resilience crop improvement programs to evaluate stability, and in identifying suitable products for various agro-ecological zones/market segments. Partnership between public sector institutions actively engaged in maize research and the private seed sector with a good market share and reach in the target countries is critical. In recent years, CIMMYT-Asia maize program have focussed on developing strong partnerships with a range of stakeholders, including public sector institutions, agricultural universities, private sector seed companies and development organization with required technical expertise and complementary strengths. Private sector partners play a key role in taking forward products to the end users through extensive multi-location farmer participatory testing of elite stress-resilient hybrids in target agro-ecologies/markets, multiplication of certified or quality declared seed, and the marketing and delivery of seed to maize farmers.

\section{Conclusions}

Climate change effects are surpassing most of the predictions and the biggest challenge, especially in the Asian tropics, is the inter-annual variability in weather patterns, uncertainty in rainfall distribution and temperature extremes. Though longterm weather trends may not be of major concern, farmers do have to deal with year-to-year variabilities that cause annual fluctuation in their farm yields. Researchers need to focus on climate-resilient technologies that insulate farmers from these inter-annual variations and yet provide improved/stable farm yields. This calls for a developing targeted product profiles that incorporate all must-have traits, such as tolerance to a set of high probability abiotic and biotic stresses along with high yields under optimal conditions for each market segment/agro-ecologies. Developing high yielding hybrids with tolerance to individual stress is an obsolete concept; developing in-built resilience to cope with inter-annual variabilities should be focused. Our regional collaborative research projects have revealed that it is possible to develop maize hybrids with improved resilience to sub-optimal conditions without comprising on yield potential under optimal conditions. This is possible through a systematic integration of novel breeding tools such as GWAS and RC-GS, strongly supported by managed stress phenotyping and double haploid technology. Constitution of base populations involving trait donors for relevant traits in targeted agroecologies/market along with elite lines with proven commercial value, their improvement for 2-3 cycles through recurrent selection using RC-GS, and evaluation of progenies across locations under managed stress phenotyping for key abiotic and biotic traits as well as under optimal conditions can provide an array of product options, including promising products across agro-ecologies, and hybrids for specific market segment/sub-agroecologies.

\section{Acknowledgements}

The authors duly acknowledge the financial support from several donor agencies, especially the United State Agency for 
International Development (USAID), Gesellschaft für Internationale Zusammenarbeit (GIZ), Germany, Syngenta Foundation for Sustainable Agriculture (SFSA) and the CGIAR Research Program on MAIZE, for the work on stress-resilient maize for Asian tropics on which this paper is based.

\section{References}

ADB (2009) Climate change threatens water, food security of 1.6 billion South Asians. https://reliefweb.int/report/.

Banziger M, Edmeades GO, Beck D, Bellon M (2000) Breeding for drought and low nitrogen tolerance: From theory to practice. Mexico, D.F.: CIMMYT.

Banziger M, Setimela PS, Hodson D, Vivek B (2006) Breeding for improved abiotic stress tolerance in maize adapted to southern Africa. Agric Water Manag. 80:212-224.

Cairns JE, Prasanna BM (2018) Developing and deploying climate-resilient maize varieties in the developing world. Current Opinion in Plant Biol. 45:226-230.

Cairns JE, Sonder K, Zaidi PH, Verhulst N, Mahuku G, Babu R, Nair SK, Das B, Govaerts B, Vinayan MT, Rashid Z, Noor JJ, Devi P, San Vicente F, Prasanna BM (2012) Maize Production in a Changing Climate: Impacts, Adaptation and Mitigation Strategies. Adv Agron. 114:1-58.

Cerrudo D, Shiliang C, Yibing Y, Carlos M, Edgar AS, Babu R, Zhang X, Trachsel S (2018) Genomic Selection Outperforms Marker Assisted Selection for Grain Yield and Physiological Traits in a Maize Doubled Haploid Population Across Water Treatments. Front Plant Sci. 9:1-12.

Edmeades GO, Bolanos J, Banziger M, Ribaut JM, White JW, Reynolds MP, Lafitte HR (1998) Improving crop yields under water-deficits in tropics. In. V.L. Chopra, R.B. Singh and A. Varma (Eds.). Crop productivity and sustainability - Shaping the future. Proceeding of the $2^{\text {nd }}$ International Crop Science Congress, New Delhi, pp. 437-451.

FAOSTAT (2018) Food and Agricultural Organization of the United Nations (FAO), FAO Statistical Database. http://faostat.fao.org.

Fedoroff NV, Battisti DS, Beachy RN, Cooper PJM, Fischhoff DA, Hodges CN, Knauf VC, Lobell D, Mazur BJ, Molden D, Reynolds MP, Ronald PC, Rosegrant MW, Sanchez PA, Vonshak A, Zhu JK (2010) Radically Rethinking Agriculture for the 21st Century. Science 327:833-834.

Fischer RA, Byerlee D, Edmeades GO (2014) Crop yields and global food security: will yield increase continue to feed the world? ACIAR Monograph No. 158. Australian Centre for International Agricultural Research: Canberra (2014) xxii + $634 \mathrm{pp}$.

Gowda M, Beyene Y, Makumbi D, Semagn K, Olsen MS, J.M. Bright, Das B, Mugo S, Prasanna BM (2018) Discovery and validation of genomic regions associated with resistance to maize lethal necrosis in four biparental populations. Mol Breed. 38:66.

Gowda M, Das B, Makumbi D, Babu R, Semagn K, Mahuku G, Olsen MS, Bright JM, Beyene Y, Prasanna BM (2015) Genome-wide association and genomic prediction of resistance to maize lethal necrosis disease in tropical maize germplasm. Theor Appl Genet. 128:1957-1968.

IFPRI 2025 Projections (2003) International model for policy analysis of agriculture commodities and trade (IMPACT) special project: Global Trend in Food Security \& Demand, IFPRI, Washington, D.C.

James C (2003) Global Review of Commercialized Transgenic Crops: 2002 Feature: Bt Maize. ISAAA Briefs No. 29. ISAAA: Ithaca, NY. http://www.isaaa.org.

Kashyapi A, Deepa AK, Anita SB, Archana PH (2012) Asian monsoon in a changing climate - Does it have impact on kharif season agriculture? International conference on "Opportunities and Challenges in Monsoon Prediction in a Changing Climate", 21-25 February 2012, Pune, India.

Lobell DB, Schlenker W, Costa-Roberts J (2011) Climate trends and global crop production since 1980. Science 333:616-620.

Makanza R, Zaman-Allah M, Cairns J E, Eyre J, Burgueño J, Ángela Pacheco, Diepenbrock C, Magorokosho C, Tarekegne A, Olsen M, Prasanna BM (2018) High-throughput method for ear phenotyping and kernel weight estimation in maize using ear digital imaging. Plant Methods 14:49 (https://doi.org/10.1186/s13007-018-0317-4).

Manton MJ, Della-Marta PM, Haylock MR (2001) Trends in extreme daily rainfall and temperature in Southeast Asia and South Pacific.:1961-1998. Int J Climat. 21:269-284.

Prasanna BM (2018) Maize in Asia - Status, Challenges and Opportunities. Book of Extended Summaries, 13th Asian Maize Conference and Expert Consultation on Maize for Food, Feed, Nutrition and Environmental Security. Ludhiana, India, Oct 8-10, 2018. CIMMYT, Mexico D.F.

Prasanna BM, Araus JL, Crossa J, Cairns JE, Palacios N, Das B, Magorokosho C (2012) High through-put and precision phenotyping for cereal breeding programs. In: Gupta PK, Varshney RK (eds) Cereal genomics-II, Springer, Heidelberg.

Rashid Z, Singh PK, Vemuri H, Zaidi PH, Prasanna BM, Nair SK (2018a) Genome-wide association study in Asia-adapted tropical maize reveals novel and explored genomic regions for sorghum downy mildew resistance. Scientific Reports 8:112.

Rashid Z, Singh PK, Zaidi PH, Vinayan MT, Sharma SS, Krishna MK, Vemula AK, Rathore A, Nair SK (2018b) Genetic analysis of resistance to post-flowering stalk rot in tropical germplasm of maize (Zea mays L.). Crop Protec. 106:42-49.

Rashid Z, Zaidi PH, Vinayan MT, Sharma SS, Srirama Setty TA (2013) Downy mildew resistance in maize (Zea mays L.) across Peronosclerospora species in lowland tropical Asia. Crop Protec. 43:183-191.

Shiferaw B, Prasanna BM, Hellin J, Banziger M (2011) Crops that feed the world 6 . Past successes and future challenges to the role played by maize in global food security. Food Security 3:307-327.

Tesfaye K, Zaidi PH, Gbegbelegbe S, Boeber C, Rahut DB, Seetharam K, Erenstein O, Stirling C (2017) Climate change impact and potential benefit of heat-tolerant maize in South Asia. Theo App Climat. 130:959-970.

Tesfaye KE, Gideon K, Cairns JE, Zaman-Allah M, Dagne W, Zaidi PH, Boote KJ, Rahut D, Erenstein O (2018) Potential benefits of drought and heat tolerance for adapting maize to climate change in tropical environments. Climate Risk Manag. 19:106-119.

Yuan Y, Jill JE, Babu R, Gowda M, Makumbi M, Magorokosho C, Zhang A, Liu $Y$, Wang $N$, Hao Z, San Vicente F, Olsen MS, Prasanna BM, Lu Y, Zhang X (2019). Genome-Wide Association Mapping and Genomic Prediction Analyses Reveal the Genetic Architecture of Grain Yield and Flowering 
Time Under Drought and Heat Stress Conditions in Maize. Front Plant Sci. 19:1-15.

Zaidi PH (2019) Management of drought stress in field phenotyping. CIMMYT, Mexico.

Zaidi PH, Rashid Z, Vinayan MT, Almeida GD, Phagna RK, Babu R (2015) QTL Mapping of Agronomic Waterlogging Tolerance Using Recombinant Inbred Lines Derived from Tropical Maize (Zea mays L). Germplasm. PLOS ONE 1-14.

Zaidi PH, Seetharam K, Krishna G, Krishnamurthy L, Gajanan S, Babu R (2016d) Genomic Regions Associated with Root Traits under Drought Stress in Tropical Maize (Zea mays L.). PLOS ONE 1-18.

Zaidi PH, Seetharam K, Vinayan MT, Nagesh P, Babu R, Vivek BS (2014) Abiotic stress-resilient maize for adaptation to climate change in Asian tropics. Book of Extended Summary. $12^{\text {th }}$ Asian Maize Conference, 30 Oct - 1 November (2014) Bangkok, Thailand.

Zaidi PH, Seetharam K, Vinayan MT, Prasanna BM (2016a) Stress-resilient maize for adaptation to climate-change effects in Asia. $7^{\text {th }}$ International Crop Science Congress, 14-19 Aug, Beijing, China.

Zaidi PH, Vinayan MT, Seetharam K (2016c) Phenotyping for abiotic stress tolerance in maize: Waterlogging stress. A field manual. CIMMYT: Hyderabad, India.

Zaidi PH, Zaman-Allah M, Trachsel S, Seetharam K, Cairns JE, Vinayan MT (2016b) Phenotyping for abiotic stress tolerance in maize - Heat stress. A field manual. CIMMYT: Hyderabad, India. 